\title{
Ultrasound-guided transversus abdominis plane block using ropivacaine and dexmedetomidine in patients undergoing caesarian sections to relieve post-operative analgesia: A randomized controlled clinical trial
}

\author{
HAITAO QIAN $^{1 *}$, QINGWEI ZHANG $^{2 *}$, PIN ZHU $^{1}$, XIAOBAO ZHANG $^{1}$, LIANG TIAN $^{1}$, \\ JIYING FENG ${ }^{1}$, YONG WU ${ }^{1}$, ZHIBIN ZHAO ${ }^{1}$ and HENGFEI LUAN ${ }^{1}$ \\ ${ }^{1}$ Department of Anesthesiology, The First People's Hospital of Lianyungang, Lianyungang, Jiangsu 222000; \\ ${ }^{2}$ Department of Anesthesiology, The First Affiliated Hospital of Nanjing Medical University, \\ Nanjing, Jiangsu 210029, P.R. China
}

Received July 16, 2019; Accepted April 21, 2020

DOI: $10.3892 /$ etm.2020.8781

\begin{abstract}
Dexmedetomidine, which is a highly selective $\alpha 2$ adrenoreceptor agonist, enhances the analgesic efficacy and prolongs the analgesic duration when administered in combination with local anesthetics. The current study aimed to evaluate the effects of dexmedetomidine combined with ropivacaine in ultrasound-guided transversus abdominis plane (TAP) block on post-operative analgesia following cesarean section (CS). A total of 70 patients scheduled for CS were divided randomly into 2 groups: The ropivacaine $(\mathrm{R})$ group, in which patients were administered bilateral $20 \mathrm{ml}$ $0.3 \%$ ropivacaine and $2 \mathrm{ml} 0.9 \%$ normal saline, and the dexmedetomidine (RD) group, in which patients were administered bilateral $20 \mathrm{ml} 0.3 \%$ ropivacaine and $2 \mathrm{ml}$ dexmedetomidine $(0.5 \mu \mathrm{g} / \mathrm{kg})$. The primary outcome was pain-free duration, and secondary outcomes included heart rate (HR) and mean blood pressure (MBP) measurements, visual analogue scale (VAS) pain scores, number of patients who required rescue analgesic, time to first request for analgesia and patient satisfaction. There was no significant difference in HR and MBP between the two groups at $1 \mathrm{~h}$ post-surgery $(\mathrm{P}>0.05)$. However, VAS pain scores decreased at 6 and $8 \mathrm{~h}$ post-surgery $[2(1-2)$ vs. $0(0-0.25)$ and 2 (2-3) vs. $0(0-1)$, respectively; $\mathrm{P}<0.05]$, pain-free duration was prolonged $(5.91 \pm 1.08$ vs. $9.62 \pm 1.46 \mathrm{~h} ; \mathrm{P}<0.05)$, the number of patients who required rescue analgesic was reduced (19 vs. 9;
\end{abstract}

Correspondence to: Dr Hengfei Luan, Department of Anesthesiology, The First People's Hospital of Lianyungang, 182 Tongguan Road, Lianyungang, Jiangsu 222000, P.R. China E-mail: luanhengfei1027@163.com

\section{${ }^{*}$ Contributed equally}

Key words: ropivacaine, dexmedetomidine, pain, transversus abdominis plane block
$\mathrm{P}<0.05)$, the time to first request for analgesia was prolonged $(7.10 \pm 1.21$ vs. $11.60 \pm 2.11 \mathrm{~h} ; \mathrm{P}<0.05)$ and patient satisfaction was improved [3.5 (3-4) vs. 4 (4-5); $\mathrm{P}<0.05]$ in the RD group compared with the R group. Furthermore, no bradycardia or hypotension was observed. In conclusion, the results of the present study demonstrated that adding $0.5 \mu \mathrm{g} / \mathrm{kg}$ dexmedetomidine to $0.3 \%$ ropivacaine used in TAP block in patients undergoing CS prolonged pain-free duration, decreased VAS pain scores, reduced the number of patients who required rescue analgesic, prolonged the time to first request for analgesia and improved the patient satisfaction without serious side effects.

\section{Introduction}

Cesarean section (CS) is one of the most common surgical procedures in China (1). The abdominal wall incision and soft tissue dissection associated with this procedure may result in moderate to severe post-operative pain, which adversely affects early ambulation and breastfeeding (2). Successful post-operative pain management following CS is crucial in order to facilitate early ambulation, shorten the recovery period and provide optimum maternal-neonatal bonding for patients (3).

Epidural analgesia and patient-controlled intravenous analgesia (PCIA) are commonly used for pain management following CS. However, these methods have certain disadvantages. For instance, epidural analgesia is often associated with lower extremity numbness and weakness, which delays early ambulation and increases the risk of thrombotic incidents (4). Furthermore, since opioids are the main drugs used in PCIA, there are concerns surrounding opiate-related complications, including sedation, nausea, vomiting, pruritus, respiratory depression and urinary retention (5). Additionally, side effects of opioids on the newborn via breast milk is another concern (6).

The transversus abdominis plane (TAP) block is a regional technique for analgesia, which provides satisfactory 
post-operative pain relief and reduces certain side effects associated with the use of opioids or epidural block $(7,8)$. Previous trials have demonstrated the efficacy of TAP block in providing post-operative analgesia following abdominal surgery $(9,10)$. However, a limitation of TAP block is its relatively short duration of analgesia due to the short duration of action of local anesthetics used in this technique. To resolve this issue, various adjuvants such as fentanyl, dexamethasone and clonidine have been used in combination with local anesthetics (11-13).

Dexmedetomidine is a potent and selective adrenergic $\alpha 2$ agonist, and numerous previous clinical trials have demonstrated that dexmedetomidine may enhance analgesic efficacy and prolong the analgesic duration when administered in combination with local anesthetics (14-16). However, no study has been performed on the effect of dexmedetomidine combined with ropivacaine in TAP block for post-CS pain management. The aim of the current study was to evaluate the efficacy of dexmedetomidine as an adjuvant to ropivacaine for TAP block in patients undergoing CS.

\section{Materials and methods}

Patients. The current study was approved by the Ethics Committee of the First People's Hospital of Lianyungang (February 2018 to February 2019). A total of 70 patients (age, 18-40 years) with an American Society of Anesthesiologists (ASA) score of I-II who were scheduled for CS under spinal anesthesia were enrolled (17). Informed written consent was obtained from all patients. Patients with a body mass index of $>30 \mathrm{~kg} / \mathrm{m}^{2}$ prior to conception, a history of allergy to any local anesthetics and/or any known contraindications for neuraxial anesthesia were excluded.

Of the 70 patients who were enrolled in the current study, 8 did not meet the inclusion criteria and 2 refused to participate. Therefore, 30 patients were randomized into the $\mathrm{R}$ and RD group using a computer-generated sequence of random numbers. The details of the series, which were generated by a statistician who did not participate in this study, were unknown to the investigators, and the numbers were hidden in sealed envelopes. The numbered envelope was opened and the card inside determined into which group the patient would be placed after the patient had entered the surgery room prior to the induction of anesthesia.

Anesthesia procedure. None of the patients were pre-medicated. After entering the surgery room, routine electrocardiogram, pulse oxygen saturation, non-invasive blood pressure (BP) and heart rate (HR) were monitored. A 20-gauge cannula was inserted into the dorsum of the patient's hand and Ringer's lactate was infused at a rate of $4-6 \mathrm{ml} / \mathrm{min}$.

Following aseptic preparation, patients were placed in the left lateral decubitus position and the skin where the spinal anesthesia was performed (the L3-4 interspace) was infiltrated with $2 \%$ lidocaine. Spinal anesthesia was performed using a 25-gauge spinal needle via a middle approach at the level of the L3-4 interspace. After confirming the free flow of cerebrospinal fluid, $10 \mathrm{mg} 0.5 \%$ hyperbaric bupivacaine was injected intrathecally over 20-30 sec. Following the induction of anesthesia, patients were immediately moved to a supine position with a $15^{\circ}$ left lateral tilt to avoid aortocaval compression. All patients received supplemental oxygen at the rate of $5 \mathrm{l} / \mathrm{min}$ via a face mask.

Surgical incision was performed when the sensory block level T6 or higher was achieved. Hypotension (systolic BP $<20 \%$ of baseline or an absolute value $<90 \mathrm{mmHg}$ ) was treated with 4-8 $\mu \mathrm{g}$ intravenous norepinephedrine, and bradycardia ( $\mathrm{HR}<50 \mathrm{bpm}$ ) was treated with $0.5 \mathrm{mg}$ intravenous atropine. The same surgical team performed the surgeries on all patients.

TAP block procedure. Following surgery, bilateral ultrasound-guided TAP block was performed. The procedure was performed under aseptic conditions. A linear high frequency ultrasound probe was placed transversely on the anterolateral abdominal wall between the iliac crest and the costal margin. Under ultrasound guidance, the three layers of muscles (external oblique, internal oblique and transversus abdominis) were identified. A 22-gauge $100 \mathrm{~mm}$ uniplex nanoline needle (Pajunk GmbH) was introduced medially in the plane of the ultrasound beam until its tip was between internal oblique and transverse abdominal muscles. Following negative aspiration, $20 \mathrm{ml} 0.3 \%$ ropivacaine and $2 \mathrm{ml}$ normal saline was administered on each side of the TAP block for the R group, and $20 \mathrm{ml}$ $0.3 \%$ ropivacaine with $2 \mathrm{ml}$ dexmedetomidine $(0.5 \mu \mathrm{g} / \mathrm{kg})$ was administered on each side of the TAP block for the RD group. Following the procedure, patients were transferred to the post-anesthesia care unit (PACU).

Studied variables. Patient demographic characteristics, including age, height, weight, BMI, ASA scores and surgery duration, were recorded. Patients were observed in the PACU for $1 \mathrm{~h}$, and $\mathrm{HR}$ and mean $\mathrm{BP}$ (MBP) were recorded every 10 min and patients then subsequently left the PACU.

Pain scores (Visual analogue scale, VAS; 0, no pain to 10 , worst imaginable pain) were assessed post-operatively at 2, 4, $6,8,10,12$ and $24 \mathrm{~h}$ (18). When VAS was $\geq 4,40 \mathrm{mg}$ parecoxib sodium was administered intravenously as a rescue analgesic (19). The number of patients who required rescue analgesic and time to first request were also recorded. Furthermore, patient satisfaction with analgesia quality $48 \mathrm{~h}$ post-surgery (Number ricrating scale, NRS 1-5; 1 , very dissatisfied; 2 , dissatisfied; 3 , slightly dissatisfied; 4, quite satisfied; 5, completely satisfied) and pain-free duration (time from the end of surgery to complaint of pain) were recorded (20).

The primary outcome of the current study was pain-free duration, and secondary outcomes included HR, MBP, VAS pain scores, number of patients who required rescue analgesic, patient satisfaction score, and time to first request of analgesic.

Statistical analysis. Sample size calculations were based on a previous pilot study (Qian et al, unpublished data). Furthermore, the sample size was calculated according to the pain-free duration. A mean pain-free duration value of $6.1 \mathrm{~h}$ and standard deviation $1.6 \mathrm{~h}$ in 10 patients who received TAP block with ropivacaine was calculated; a total of 27 patients were required for each group to detect significant differences between groups of $20 \%$ with $\alpha=0.05$ two-tailed and $\beta=0.1$. This number was raised to 35 , and a total of 70 patients were enrolled to take into account potential drop-outs in both groups, allowing a predicted $15 \%$ drop-out rate in both groups. 
Table I. Comparison of demographics and surgery duration between groups $\mathrm{R}$ and $\mathrm{RD}$.

\begin{tabular}{lccc}
\hline Variable & $\begin{array}{c}\text { Group R } \\
(\mathrm{n}=30)\end{array}$ & $\begin{array}{c}\text { Group RD } \\
(\mathrm{n}=30)\end{array}$ & P-value \\
\hline Age, years & $26.4 \pm 4.0$ & $27.8 \pm 5.6$ & 0.258 \\
Height, $\mathrm{cm}$ & $162.7 \pm 4.6$ & $163.6 \pm 4.5$ & 0.450 \\
Weight, $\mathrm{kg}$ & $75.5 \pm 7.1$ & $75.8 \pm 6.9$ & 0.869 \\
BMI, $\mathrm{kg} / \mathrm{m}^{2}$ & $28.5 \pm 2.7$ & $28.3 \pm 2.5$ & 0.760 \\
ASA score, $\mathrm{I} / \mathrm{II}$ & $23 / 7$ & $25 / 5$ & 0.374 \\
Surgery duration, min & $63.5 \pm 12.2$ & $65.9 \pm 13.4$ & 0.459 \\
\hline
\end{tabular}

Data are expressed as mean \pm standard deviation or number of patients. $\mathrm{R}$, ropivacaine; $\mathrm{RD}$, ropivacaine with dexmedetomidine; BMI, body mass index; ASA, American Society of Anesthesiologists

Table II. Comparison of visual analogue scale scores between groups $\mathrm{R}$ and $\mathrm{RD}$.

\begin{tabular}{lccc}
\hline $\begin{array}{l}\text { Time post- } \\
\text { surgery, h }\end{array}$ & $\begin{array}{c}\text { Group R } \\
(\mathrm{n}=30)\end{array}$ & $\begin{array}{c}\text { Group RD } \\
(\mathrm{n}=30)\end{array}$ & P-value \\
\hline 2 & $0(0.00-0.00)$ & $0(0.00-0.00)$ & 1.000 \\
4 & $0(0.00-0.00)$ & $0(0.00-0.00)$ & 0.690 \\
6 & $2(1.00-2.00)$ & $0(0.00-0.25)$ & $<0.001^{\mathrm{a}}$ \\
8 & $2(2.00-3.00)$ & $0(0.00-1.00)$ & $<0.001^{\mathrm{a}}$ \\
10 & $2(1.00-2.00)$ & $2(2.00-2.25)$ & 0.472 \\
12 & $2(1.75-2.00)$ & $2(2.00-2.00)$ & 0.841 \\
24 & $1(0.00-1.00)$ & $1(0.75-1.00)$ & 0.224 \\
\hline
\end{tabular}

${ }^{\mathrm{a}} \mathrm{P}<0.05$. Data are expressed as median (interquartile range). $\mathrm{R}$, ropivacaine; $\mathrm{RD}$, ropivacaine with dexmedetomidine.

Statistical analyses were performed using SPSS software (version 16.0; SPSS, Inc.). Continuous numerical data are expressed as mean \pm standard deviation or median and interquartile range. Categorical data are expressed as frequencies or percentages. Normally distributed numerical data between groups were analyzed using the Student's t-test, skewed data between groups were analyzed using the Mann-Whitney U-test, and categorical variables were analyzed using Fisher's exact test or Pearson's $\chi^{2}$ test as applicable. All tests were two-tailed. $\mathrm{P}<0.05$ was considered to indicate a statistically significant difference.

\section{Results}

There were no significant differences in the demographic characteristics of the patients and surgery duration between the two groups $(\mathrm{P}>0.05$; Table I).

Heart rate was compared between groups $\mathrm{R}$ and $\mathrm{RD}$ at the observed time-points $(79.0 \pm 8.3$ vs. $78.0 \pm 8.8$, $77.2 \pm 8.1$ vs. $76.9 \pm 7.2,75.4 \pm 7.3$ vs. $74.6 \pm 7.5,74.4 \pm 7.1$ vs. $73.9 \pm 7.6$, $73.7 \pm 7.7$ vs. $71.3 \pm 7.8,72.2 \pm 8.2$ vs. $70.8 \pm 8.0$, respectively; $\mathrm{P}>0.05$; Fig. 1). Additionally, mean blood pressure was similar between groups at the same time-points $(91.9 \pm 9.1$ vs. 88.6 \pm 8.3 ,

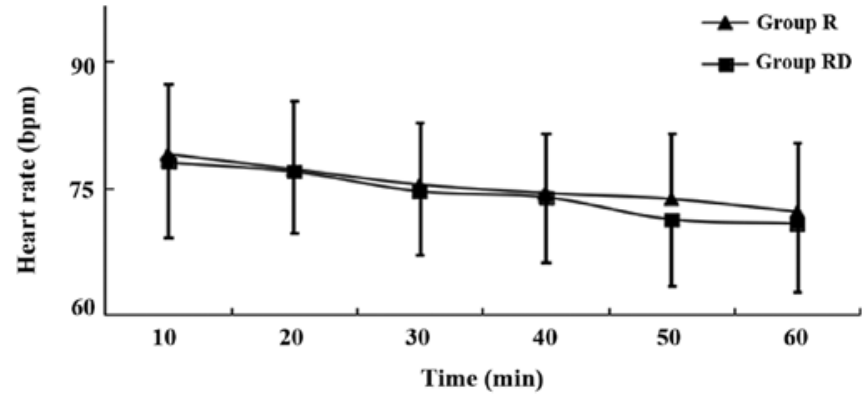

Figure 1. Post-operative mean heart rate in groups R and RD at the observed time-points. Bar indicates standard deviation. R, ropivacaine; RD, ropivacaine with dexmedetomidine; bpm, beats per minute.

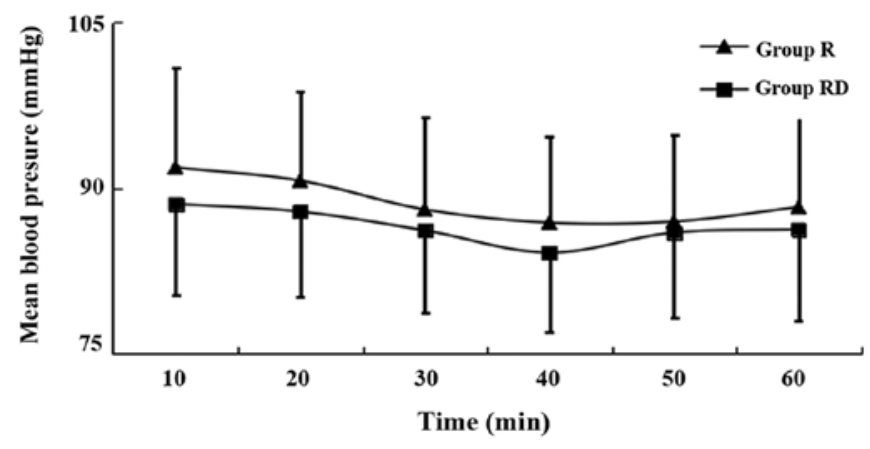

Figure 2. Post-operative mean blood pressure in groups R and RD at the observed time-points. Bar indicates standard deviation. R, ropivacaine; RD, ropivacaine with dexmedetomidine; $\mathrm{mmHg}$, millimeters of mercury.

$90.7 \pm 8.0$ vs. $87.9 \pm 7.7,88.1 \pm 8.4$ vs. $86.2 \pm 7.5,86.9 \pm 7.8$ vs. $84.2 \pm 7.2$, $87.0 \pm 7.9$ vs. $86.0 \pm 7.6,88.3 \pm 8.1$ vs. $86.3 \pm 8.2$; P>0.05; Fig. 2 ). No patients developed hypotension or bradycardia in either group during this time period.

Post-operative VAS pain scores were significantly lower the RD group at 6 and $8 \mathrm{~h}$ compared with those in the R group. However, there was no significant difference in scores between groups at 2, 4, 10, 12 and $24 \mathrm{~h}$ (Table II).

Compared with the $\mathrm{R}$ group, the pain-free duration and first request for analgesia were significantly prolonged in the RD group (Table III). The number of patients who required rescue analgesia was also significantly lower in the RD group compared with that in the R group (Table III). Additionally, patient satisfaction scores were significantly higher in the $\mathrm{RD}$ group compared with the $\mathrm{R}$ group during the initial $48 \mathrm{~h}$ post-surgery (Table III).

\section{Discussion}

In the current prospective study of patients undergoing CS, the results demonstrated that the addition of $0.5 \mu \mathrm{g} / \mathrm{kg}$ dexmedetomidine to $0.3 \%$ ropivacaine used in TAP block prolonged pain-free duration and time to first request for analgesia, reduced the number of patients who required rescue analgesic and improved patient satisfaction without serious side effects.

Ultrasound-guided TAP block affects the T9 to L1 nerve roots and is recommended to be used in lower abdominal surgery (21). It has also been introduced as an effective component of multimodal analgesia following CS $(9,22)$. 
Table III. Comparison of post-operative variables between groups R and RD.

\begin{tabular}{lccc}
\hline Post-operative variable & Group R $(\mathrm{n}=30)$ & Group RD $(\mathrm{n}=30)$ & P-value \\
\hline Pain-free duration, $\mathrm{h}$ & $5.91 \pm 1.08$ & $9.62 \pm 1.46$ & $<0.001$ \\
No. of patients who required rescue analgesic & 19 & 9 & $0.010^{\mathrm{a}}$ \\
Time to first request for analgesia, $\mathrm{h}$ & $7.10 \pm 1.21$ & $11.60 \pm 2.11$ & $<0.001^{\mathrm{a}}$ \\
Patient satisfaction score & $3.5(3-4)$ & $4(4-5)$ & $<0.001^{\mathrm{a}}$
\end{tabular}

${ }^{\mathrm{a}} \mathrm{P}<0.05$. Data are expressed as mean \pm standard deviation, patient of number or median (interquartile range). R, ropivacaine; RD, ropivacaine with dexmedetomidine.

Ropivacaine is a member of the amino amide class of local anesthetics. In the current study, ropivacaine was used as the local anesthetic for TAP block as it has higher safety margin and lower levels of cardiac toxicity compared with bupivacaine (23). Previous studies have demonstrated that $0.25-0.5 \%$ ropivacaine for TAP block is valid $(24,25)$. Therefore, $0.3 \%$ ropivacaine was used for TAP block in the current study. However, the relatively short duration of analgesia is still a major limitation of this technique. Recently, adjuvants used in conjugation with local anesthetics in order to prolong analgesia duration have become a focus of interest in the field of peripheral nerve block (26).

Dexmedetomidine, which is a highly selective $\alpha 2$ adrenoreceptor agonist, is an ideal adjuvant to local anesthetics in numerous regional blocks. Hetta et al (27) reported that epidural infusion of dexmedetomidine combined with bupivacaine reduced morphine consumption delayed the time to first analgesic supplementation and decreased pain intensity in patients undergoing major abdominal cancer surgery and epidural blocks. Ganesh and Krishnamurthy (28) reported that dexmedetomidine combined with bupivacaine administered intrathecally exhibited a faster onset of motor and sensory block and prolonged the duration of anesthesia in patients undergoing spinal block. Mangal et al (15) demonstrated that the addition $1 \mu \mathrm{g} / \mathrm{kg}$ dexmedetomidine to $0.75 \%$ ropivacaine in supraclavicular brachial plexus block prolonged the duration of sensory and motor block. Furthermore, Mohta et al (29) reported that paravertebral block using $1 \mu \mathrm{g} / \mathrm{kg}$ dexmedetomidine combined with $0.5 \%$ bupivacaine provided longer duration of anesthesia with decreased post-operative opioid consumption and lower incidence of nausea and vomiting compared with bupivacaine alone. Aksu et al (30) demonstrated that addition of dexmedetomidine to bupivacaine in TAP block decreased post-operative pain scores and morphine consumption, and increased patient satisfaction in patients undergoing lower abdominal surgery. Thus, all of these previous studies demonstrated that dexmedetomidine may enhance analgesic efficacy and prolong the analgesic duration of local anesthetics when administered in combination with local anesthetics.

In the current study, the results indicated that when compared with $0.3 \%$ ropivacaine alone, adding $0.5 \mu \mathrm{g} / \mathrm{kg}$ dexmedetomidine to $0.3 \%$ ropivacaine in TAP block prolonged pain-free duration, decreased post-operation VAS pain scores at 6 and $8 \mathrm{~h}$ post-surgery, reduced the number of patients who required rescue analgesic, prolonged the time to first request for analgesic and improved patient satisfaction without serious side effects. These results were consistent with a previous study by Ramya et al (31), which concluded that the addition of dexmedetomidine to bupivacaine in TAP block prolonged the time to first request of rescue analgesia and reduced the total dose of opioid requirement in the first $24 \mathrm{~h}$ post-CS. However, Ding et al (32) reported that adding dexmedetomidine did not significantly improve the quality or duration of TAP block. Different does and concentrations of ropivacaine and dexmedetomidine and analgesics used post-surgery may explain these differences in the results.

Bradycardia and hypotension are the most common side effects of dexmedetomidine when administered intravenously (33). Therefore, HR and MBP were continuously monitored, and the results were recorded every $10 \mathrm{~min}$ until the patients left the PACU. The results demonstrated a slight decrease in HR and MBP in the two groups, which was not significantly different between the groups. In addition, none of the patients exhibited bradycardia and/or hypotension during their time in the PACU.

A meta-analysis revealed that dexmedetomidine combined with ropivacaine in brachial plexus block had a better analgesic effect compared with ropivacaine alone, Meanwhile, there was no difference in the incidence of bradycardia and hypotension (34). Mangal et al (15) reported that two patients exhibited bradycardia $(\mathrm{HR}<60 \mathrm{bpm})$ in the dexmedetomidine $(1.0 \mu \mathrm{g} / \mathrm{kg})$ group when dexmedetomidine was used as an adjuvant to ropivacaine for supraclavicular brachial plexus. The differences in the definition of bradycardia ( $\mathrm{HR}<50 \mathrm{bpm})$ and concentration of dexmedetomidine $(0.5 \mu \mathrm{g} / \mathrm{kg})$ in the current study may explain the difference in results.

The current study had certain limitations. First, the present randomized controlled double-blinded trial was conducted at a single center. Further clinical trials are required at multiple centers in order to generalize the results. Second, whether the action of dexmedetomidine was related to systemic absorption or pure local effect was not fully elucidated. Further research is necessary to determine the plasma levels of dexmedetomidine. Third, the onset of action of the TAP block was not assessed precisely as the effect of the spinal block may not have worn off when the TAP block was performed. Further studies concerning patients accepting general anesthesia rather than spinal anesthesia may resolve this issue.

In conclusion, the results of the current study demonstrated that the addition $0.5 \mu \mathrm{g} / \mathrm{kg}$ dexmedetomidine to $0.3 \%$ ropivacaine used in TAP block in patients undergoing CS prolonged 
pain-free duration, decreased VAS pain scores, reduced the number of patients who required rescue analgesia, prolonged the time of first request for analgesia and improved patient satisfaction without serious side effects.

\section{Acknowledgements}

Not applicable.

\section{Funding}

This study was supported by the Hansoh Foundation of Lianyungang (grant no. QN1801).

\section{Availability of data and materials}

The datasets used and/or analyzed during the current study are available from the corresponding author on reasonable request.

\section{Authors' contributions}

HQ and QZ designed the study, performed the transversus abdominis plane blocks and wrote the first draft of the manuscript. PZ, XZ, LT and JF collected the clinical data. YW and $\mathrm{ZZ}$ analyzed the data and interpreted the results. HL designed the study and revised the manuscript. All authors read and approved the final manuscript.

\section{Ethics approval and consent to participate}

The current study was approved by the Ethics Committee of the First People's Hospital of Lianyungang. Informed written consent was obtained from all patients.

\section{Patient consent for publication}

Not applicable.

\section{Competing interests}

The authors declare that they have no competing interests.

\section{References}

1. Li HT, Luo S, Trasande L, Hellerstein S, Kang C, Li JX, Zhang Y, Liu JM and Blustein J: Geographic variations and temporal trends in cesarean delivery rates in China, 2008-2014. JAMA 317: 69-76, 2017.

2. Chou R, Gordon DB, de Leon-Casasola OA, Rosenberg JM, Bickler S, Brennan T, Carter T, Cassidy CL, Chittenden EH, Degenhardt E, et al: Management of postoperative pain: A clinical practice guideline from the American pain society, the American society of regional anesthesia and pain medicine, and the American society of Anesthesiologists' Committee on Regional Anesthesia, Executive Committee, and Administrative Council. J Pain 17: 131-157, 2016.

3. Wagner-Kovacec J, Povalej-Brzan P and Mekis D: Efficacy of continuous in-wound infusion of levobupivacaine and ketorolac for post-caesarean section analgesia: A prospective, randomised, double-blind, placebo-controlled trial. BMC Anesthesiol 18: 165, 2018.

4. Barrington MJ, Olive D, Low K, Scott DA, Brittain J and Choong P: Continuous femoral nerve blockade or epidural analgesia after total knee replacement: A prospective randomized controlled trial. Anesth Analg 101: 1824-1829, 2005.
5. Madadi P, Ross CJ, Hayden MR, Carleton BC, Gaedigk A, Leeder JS and Koren G: Pharmacogenetics of neonatal opioid toxicity following maternal use of codeine during breastfeeding: A case-control study. Clin Pharmacol Ther 85: 31-35, 2009.

6. Busch DW: Clinical management of the breast-feeding mother-infant dyad in recovery from opioid dependence. J Addict Nurs 27: 68-77, 2016.

7. Mittal T, Dey A, Siddhartha R, Nali A, Sharma B and Malik V: Efficacy of ultrasound-guided transversus abdominis plane (TAP) block for postoperative analgesia in laparoscopic gastric sleeve resection: A randomized single blinded case control study. Surg Endosc 32: 4985-4989, 2018.

8. Shaker TM, Carroll JT, Chung MH, Koehler TJ, Lane BR, Wolf AM and Wright GP: Efficacy and safety of transversus abdominis plane blocks versus thoracic epidural anesthesia in patients undergoing major abdominal oncologic resections: A prospective, randomized controlled trial. Am J Surg 215: 498-501, 2018.

9. Kupiec A, Zwierzchowski J, Kowal-Janicka J, Goździk W, Fuchs T, Pomorski M, Zimmer M and Kübler A: The analgesic efficiency of transversus abdominis plane (TAP) block after caesarean delivery. Ginekol Pol 89: 421-424, 2018.

10. Punekar IRA, Koltz PF, Smith DI, Tran NH, Chibber AK, Sbitany H, Girotto JA and Morrison C: The evolution of iliac bone graft donor site analgesia in cleft patients: Transversus abdominis plane block is safe and efficacious. Ann Plast Surg 81: 441-443, 2018.

11. Farooq N, Singh RB, Sarkar A, Rasheed MA and Choubey S: To evaluate the efficacy of fentanyl and dexmedetomidine as adjuvant to ropivacaine in brachial plexus block: A double-blind, prospective, randomized study. Anesth Essays Res 11: 730-739, 2017.

12. Sakae TM, Marchioro P, Schuelter-Trevisol F and Trevisol DJ: Dexamethasone as a ropivacaine adjuvant for ultrasound-guided interscalene brachial plexus block: A randomized, double-blinded clinical trial. J Clin Anesth 38: 133-136, 2017.

13. Singh R, Kumar N, Jain A and Joy S: Addition of clonidine to bupivacaine in transversus abdominis plane block prolongs postoperative analgesia after cesarean section. J Anaesthesiol Clin Pharmacol 32: 501-504, 2016

14. Rwei AY, Sherburne RT, Zurakowski D, Wang B and Kohane DS: Prolonged duration local anesthesia using liposomal bupivacaine combined with liposomal dexamethasone and dexmedetomidine. Anesth Analg 126: 1170-1175, 2018.

15. Mangal V, Mistry T, Sharma G, Kazim M, Ahuja N and Kulshrestha A: Effects of dexmedetomidine as an adjuvant to ropivacaine in ultrasound-guided supraclavicular brachial plexus Block: A prospective, randomized, double-blind study. J Anaesthesiol Clin Pharmacol 34: 357-361, 2018.

16. Bakr MA, Mohamed SA, Mohamad MF, Mohamed MA, El Sherif FA, Mosad E and Abdel-Hamed MF: Effect of dexmedetomidine added to modified pectoral block on postoperative pain and stress response in patient undergoing modified radical mastectomy. Pain Physician 21: E87-E96, 2018.

17. Knuf KM, Maani CV and Cummings AK: Clinical agreement in the American Society of Anesthesiologists physical status classification. Perioper Med (Lond) 7: 14, 2018.

18. Bharti N, Sardana DK and Bala I: The analgesic efficacy of dexmedetomidine as an adjunct to local anesthetics in supraclavicular brachial plexus block: A randomized controlled trial. Anesth Analg 121: 1655-1660, 2015.

19. Inthigood N, Lertbunnaphong T and Jaishuen A: Efficacy of a single 40-mg intravenous dose of parecoxib for postoperative pain control after elective cesarean delivery: A double-blind randomized placebo-controlled trial. J Obstet Gynaecol Res 43: 92-99, 2017.

20. Xu J, Yang X, Hu X, Chen X, Zhang J and Wang Y: Multilevel thoracic paravertebral block using ropivacaine with/without dexmedetomidine in video-assisted thoracoscopic surgery. J Cardiothorac Vasc Anesth 32: 318-324, 2018

21. Shin HJ, Oh AY, Baik JS, Kim JH, Han SH and Hwang JW: Ultrasound-guided oblique subcostal transversus abdominis plane block for analgesia after laparoscopic cholecystectomy: A randomized, controlled, observer-blinded study. Minerva Anestesiol 80: 185-193, 2014.

22. Narasimhulu DM, Scharfman L, Minkoff H, George B, Homel P and Tyagaraj K: A randomized trial comparing surgeon-administered intraoperative transversus abdominis plane block with anesthesiologist-administered transcutaneous block. Int J Obstet Anesth 35: 26-32, 2018. 
23. Rashmi HD and Komala HK: Effect of Dexmedetomidine as an Adjuvant to $0.75 \%$ ropivacaine in interscalene brachial plexus block using nerve stimulator: A prospective, randomized double-blind study. Anesth Essays Res 11: 134-139, 2017.

24. De Oliveira GS Jr, Fitzgerald PC, Marcus RJ, Ahmad S and McCarthy RJ: A dose-ranging study of the effect of transversus abdominis block on postoperative quality of recovery and analgesia after outpatient laparoscopy. Anesth Analg 113: 1218-1225, 2011.

25. Abdul Jalil RM, Yahya N, Sulaiman O, Wan Mat WR, Teo R, Izaham A and Rahman RA: Comparing the effectiveness of ropivacaine $0.5 \%$ versus ropivacaine $0.2 \%$ for transabdominis plane block in providing postoperative analgesia after appendectomy. Acta Anaesthesiol Taiwan 52: 49-53, 2014.

26. Abd-Elshafy SK, Abdallal F, Kamel EZ, Edwar H, Allah EA, Maghraby HH, Sayed JA, Ali MS, Elkhayat H and Mahran GS: Paravertebral dexmedetomidine in video-assisted thoracic surgeries for acute and chronic pain prevention. Pain Physician 22: 271-280, 2019

27. Hetta DF, Fares KM, Abedalmohsen AM, Abdel-Wahab AH, Elfadl GM and Ali WN: Epidural dexmedetomidine infusion for perioperative analgesia in patients undergoing abdominal cancer surgery: Randomized trial. J Pain Res 11: 2675-2685, 2018.

28. Ganesh M and Krishnamurthy D: A Comparative study of dexmedetomidine and clonidine as an adjuvant to intrathecal bupivacaine in lower abdominal surgeries. Anesth Essays Res 12: 539-545, 2018.
29. Mohta M, Kalra B, Sethi AK and Kaur N: Efficacy of dexmedetomidine as an adjuvant in paravertebral block in breast cancer surgery. J Anesth 30: 252-260, 2016.

30. Aksu R, Patmano G, Biçer C, Emek E and Çoruh AE: Efficiency of bupivacaine and association with dexmedetomidine in transversus abdominis plane block ultrasound guided in postoperative pain of abdominal surgery. Rev Bras Anestesiol 68: 49-56, 2018 (In Portuguese).

31. Ramya Parameswari A and Udayakumar P: Comparison of efficacy of bupivacaine with dexmedetomidine versus bupivacaine alone for transversus abdominis plane block for post-operative analgesia in patients undergoing elective caesarean section. J Obstet Gynaecol India 68: 98-103, 2018.

32. Ding W, Li W, Zeng X, Li J, Jiang J, Guo C and Li W: Effect of adding dexmedetomidine to ropivacaine on ultrasound-guided dual transversus abdominis plane block after gastrectomy. J Gastrointest Surg 21: 936-946, 2017.

33. Keating GM: Dexmedetomidine: A review of its use for sedation in the intensive care setting. Drugs 75: 1119-1130, 2015.

34. Dai W, Tang $M$ and He K: The effect and safety of dexmedetomidine added to ropivacaine in brachial plexus block: A meta-analysis of randomized controlled trials. Medicine (Baltimore) 97: e12573, 2018 